\title{
THEMATIC ANALYSIS OF THE SOCIAL ASPECTS OF NORDIC WALKING: THE INSTRUCTORS' PERSPECTIVE
}

original paper

( ) University School of Physical Education in Wroclaw

DOI: https://doi.org/10.5114/hm.2020.89909

\section{MARTA ANNA ZURAWIK}

Independent researcher

\section{ABSTRACT}

Purpose. The health benefits of Nordic walking have been widely examined in previous studies. However, the social benefits of the activity are still unknown. The aim of this study is to explore various social aspects of Nordic walking from the instructors' perspective related to the activity participation.

Methods. Overall, 14 Nordic walking instructors contacted electronically via the International Nordic Walking Federation instructor database completed open-ended questionnaires. The open-ended questionnaire consisted of 17 questions, grouped in sections (socio-demographic characteristics, career background, motives for becoming a Nordic walking instructor, characteristics of Nordic walking groups, means of promoting Nordic walking in local communities, group dynamics, and perceived barriers to participation). The data were content-analysed by using qualitative-data-management software MAXQDA 10.

Results. Participation in Nordic walking focused on building and maintaining strong social relationships between practitioners and instructors, which offered social and emotional support within the groups. The study identified environmental and psychological barriers to Nordic walking. Environmental barriers were associated with the weather and seasonal conditions, and the diversity of built and natural environments. Psychological barriers to Nordic walking referred to a negative image of walking with poles.

Conclusions. Nordic walking was suitable for people who searched for an opportunity to exercise with the intention for socialising and improving health.

Key words: Nordic walking, instructor, social support, physical activity, environmental barriers, psychological barriers

\section{Introduction}

Nordic walking, also known as walking with poles, adds new options for choosing walking as a pastime, providing an alternative to other types of walking [1,2]. It combines the classic cross-country skiing technique with fitness walking, which can be summarised as an enhancement of a normal arm swing that occurs when walking, with the addition of specially designed poles [3]. The benefits and desired fitness and health effects may be achieved by following the exercise precisely, especially in the initial stages of learning the correct technique of walking with poles [4]. The vital role in mastering the basic Nordic walking technique is played by instructors. In addition, instructors are informal conductors in walking groups who share positive experiences of the activity and promote Nordic walking in local communities in order to change public awareness of physical activity and implement active lifestyle habits [5]. Over the last 2 decades, Nordic walking has received increasing academic attention in exploring its positive effects on groups of people with special needs and various medical problems.

Nordic walking is a suitable form of physical activity for preventing or managing symptoms of physical inactivity, such as obesity [6], back pain [7], diabetes mellitus [8], acute coronary syndrome [9], and moderate to severe heart failure [10].

Scientific evidence suggests that Nordic walking increases the exercise intensity owing to the active use of the poles, which results in an increased use of the upper body involved in the poling action, greater arm and shoulder movements $[4,11]$. The activity evidently increases oxygen consumption by an average of $20 \%$,

Correspondence address: Marta Anna Zurawik, 2 Wilson Avenue, Wigan, WN6 7HD, United Kingdom,

e-mail: martazurawik@hotmail.com

Received: October 29, 2018

Accepted for publication: September 3, 2019

Citation: Zurawik MA. Thematic analysis of the social aspects of Nordic walking: the instructors' perspective. Hum Mov. 2020;21(2):9-18; doi: https://doi.org/10.5114/hm.2020.89909. 
caloric expenditure by $22 \%$, and heart rate response by $16 \%$ in comparison with normal walking $[4,12-15]$.

Nordic walking is also applied in various rehabilitation programs. For example, several studies revealed that Nordic walking was an effective exercise for patients suffering from Parkinson's disease [16, 17]. The results of these studies suggested that Nordic walking training increased patients' daily physical activity levels, improved functional mobility, and reduced daily symptoms of Parkinson's disease. The activity also benefits rehabilitation of breast cancer survivors $[18,19]$. Fischer et al. [20] reported a significant reduction in shoulder problems among women with breast cancer immediately after the Nordic walking intervention. In contrast, the psychological and social benefits of the activity have attracted recent attention, which is still very limited [21-23].

The growing academic literature on the social aspects of physical activity, including walking, has acknowledged that adults are more likely to become active and maintain an active lifestyle if they have opportunities to interact, communicate with others, and share experiences [22, 24, 25]. Moreover, interactions of individuals who consider themselves as a part of a group with other members generate a sense of belonging and identity with a particular group. This often leads to perceiving and understanding the world from a group collective perspective [26-28]. In particular, social support for regular physical activity has been one of the most studied psychosocial determinants of participation in physical activity. Several studies have found strong positive associations between physical activity and social support [24, 29,30], and friend and family support has been found to be the most beneficial influence in the participation in physical activity across a wide range of populations [31, 32]. Furthermore, group physical activities provide social settings for people to share interests, socialise, develop and strengthen friendships. By contrast, a lack of social support from family and friends is associated with lower levels of physical activity, especially among women [33].

Social groups often embrace certain distinctive cultural elements, such as a shared set of identifiable values and meanings that are transmitted socially as participants interact with one another [34]. In the case of Nordic walking, the subculture can be perceived through equipment, competence, and skill. In order to become a member of the Nordic walking community, all practitioners need to be trained to master a specific walking technique during specially designed courses [5, 35]. People are taught how to hold the walking poles and use them to the best effect in a variety of condi- tions. All Nordic walking groups are organised and supervised by instructors, who provide advice and guidance on how to incorporate Nordic walking in an exercising regime. Nordic walking instructors act as activity promoters, leaders, and organisers [5]. They strive to change the public awareness of physical activity and implement active lifestyle habits in the local communities. Owing to the instructors' efforts, Nordic walking practitioners perceive themselves to be competent and skilful members of the community within which walking with sticks and healthy living go handin-hand. Therefore, in Nordic walking, an important part of motivation is satisfaction with the performance and achievement.

The purpose of this study is to address the gap in knowledge on the social benefits of Nordic walking by identifying the potential role of social factors in the activity participation. This study focuses on exploring the social aspects of Nordic walking from the instructors' perspective only, as it analyses social interactions, motivations for participation, and perceived barriers and enablers in Nordic walking practice.

Inasmuch, this research is solely based on the experiences of the instructors; the study should be regarded as an introduction to further research into social and psychological benefits of Nordic walking.

\section{Material and methods}

The qualitative approach provides an opportunity for a detailed investigation of personal experiences and meanings, which is difficult to capture by applying quantitative methods.

Because of a low response rate from British Nordic walking instructors who agreed to participate, an openended questionnaire was chosen as a research instrument in order to approach an international group of Nordic walking instructors. The choice of open-ended questionnaire for the study was to simulate interview questions since the procedures for developing questionnaires and interviews are similar.

The convenience sampling method, based on the participants' availability, ease of data collection, and limited resources available, was employed in the study. The international group of Nordic walking instructors was contacted electronically via the International Nordic Walking Federation (INWA) instructor database (https://www.inwa-nordicwalking.com/find-aninstructor/) between September 2012 and December 2012. The instructors interested in the study received a written open-ended questionnaire in a Word .doc format in English, including a research information 
sheet. The information sheet referred to the purpose of the study, a broad indication of the survey coverage, and assurances of confidentiality and anonymity. The participants were asked to complete the questionnaire to the best of their knowledge on the subjects. The purpose of open-ended questions was to simulate interview questions since the procedures for developing questionnaires and interviews are similar [36].

\section{Participants}

A total of 14 Nordic walking instructors completed the open-ended questionnaires. The sample comprised 9 females and 5 males. The detailed socio-demographic characteristics of the participants, including gender, nationality, age group, career background, and length of employment as a Nordic walking instructor, are presented in Table 1.

\section{Measures}

The questionnaire consisted of 17 questions, grouped in 6 sections. The first part assessed the socio-demographic characteristics (age, gender, nationality, marital status, and employment status). The second part collected information about career background, motives for practising Nordic walking and becoming a Nordic walking instructor. Next, respondents were asked to share information about the Nordic walking groups (number of groups, sessions, intensity and duration of sessions) and means of promoting Nordic walking in local communities (targeting particular age groups, health conditions, etc.). The fourth part investigated the social aspects of Nordic walking. The fifth part focused on describing the perceived barriers that may have affected regular participation and experiences in Nordic walking. In the last section, the participants had the opportunity to add comments.

Data analysis

The open-ended questionnaires were content-analysed by using qualitative-data-management software MAXQDA 10 [37]. Content analysis is a popular method for textual investigation. It offers convenience in simplifying and reducing large amounts of data into organised segments [38]. During the initial stage, the author developed initial themes, and for each deductive theme, inductive codes were created grouping together recurring phrases and keywords in the text featuring similar content. This step of analysis focused on capturing the complexity of meanings to produce some level of generalisation.

The author followed a consistent and systematic coding procedure and data analysis in order to reduce biases and ensure the integrity of the study. Furthermore, the analysis and the interpretation of the data were discussed and validated by senior researchers.

In the final step, the author refined the sub-themes and generated a thematic map of the data analysis (Table 2).

\section{Ethical approval}

The research related to human use has complied with all the relevant national regulations and institutional policies, has followed the tenets of the Declaration of Helsinki and the guidelines of the University

Table 1. Socio-demographic characteristics of respondents

\begin{tabular}{|c|c|c|c|c|}
\hline Gender & Nationality & Age group (years) & Years as instructor & Career background \\
\hline Female & British & $40-49$ & $1-2$ & Nursing \\
\hline Female & American & $50-59$ & $>5$ & Education \\
\hline Female & British & $<40$ & $\leq 1$ & Line manager \\
\hline Male & Danish & $>70$ & $>5$ & Logistics \\
\hline Male & British & $60-69$ & $3-4$ & Army \\
\hline Female & American & $40-49$ & $>5$ & Fitness instructor \\
\hline Female & Italian & $40-49$ & $2-3$ & Marketing \\
\hline Female & Dutch & $50-59$ & $>5$ & Physiotherapy \\
\hline Female & German & $<40$ & $3-4$ & Sports therapy \\
\hline Female & French & $40-49$ & $2-3$ & Communication \\
\hline Male & British & $<40$ & $2-3$ & Fitness instructor \\
\hline Female & Finnish & $60-69$ & $>5$ & Health care \\
\hline Male & Canadian & $50-59$ & $1-2$ & Marketing and sales \\
\hline Male & British & $>70$ & $2-3$ & Engineering \\
\hline
\end{tabular}




\section{HUMAN MOVEMENT}

M. Zurawik, The social aspects of Nordic walking

Table 2. Thematic map of the data analysis

\begin{tabular}{|c|c|c|}
\hline Main themes & Sub-themes & Key words \\
\hline \multirow{4}{*}{$\begin{array}{l}\text { Theme } 1 . \\
\text { Benefits of Nordic walking }\end{array}$} & Instant benefits & \\
\hline & Whole body workout & Nordic walking poles \\
\hline & Physical therapy & \\
\hline & Suitable for everyone & $\begin{array}{l}\text { Older adults } \\
\text { Women } \\
\text { Children }\end{array}$ \\
\hline \multirow{4}{*}{$\begin{array}{c}\text { Theme } 2 \text {. } \\
\text { Motives for Nordic walking }\end{array}$} & Leisure career & $\begin{array}{l}\text { Get people active } \\
\text { Need for instructors } \\
\text { Passion for Nordic walking } \\
\text { Own business }\end{array}$ \\
\hline & Alternative exercise & \\
\hline & Rehabilitation & \\
\hline & Health and fitness & Whole body workout \\
\hline \multirow{3}{*}{$\begin{array}{c}\text { Theme } 3 . \\
\text { Social world of Nordic walking }\end{array}$} & Socialising & \\
\hline & Friendship & \\
\hline & Social sharing and support & $\begin{array}{l}\text { Friends and family } \\
\text { Nordic walking instructors }\end{array}$ \\
\hline \multirow{3}{*}{$\begin{array}{l}\text { Theme } 4 . \\
\text { Barriers to Nordic walking }\end{array}$} & Environmental & $\begin{array}{l}\text { Weather } \\
\text { Access } \\
\text { Darkness }\end{array}$ \\
\hline & Psychological & Negative image \\
\hline & Social & Extensive socialising during workout \\
\hline
\end{tabular}

of Bolton Code of Practice for Ethical Standards in Research Involving Human Participants. Prior to the commencement of the study, all procedures involving human participants were granted ethical approval by the School Research Ethics Committee.

\section{Informed consent}

Informed consent has been obtained from all individuals included in this study.

\section{Results}

\section{Benefits of Nordic walking}

All respondents perceived Nordic walking as an 'inclusive activity' and 'suitable for everyone,' regardless of age, fitness, and health status, as the activity offers diverse forms of exercising. For example, a Canadian instructor noted that 'all ages that can walk qualify; those who choose walking as their form of exercise'. Nordic walking practice varies from social to competitive modes and it can be practised at 3 levels of advancement, depending on health needs and the endurance of practitioners. Nordic walking for health is typically practised in groups supervised by expert instructors. It can be viewed as a form of leisure owing to its links to outdoors and social benefits. The activity is suited for those who usually abstain from physical activity as it focuses on improving and maintaining health and well-being. Fitness Nordic walking consists of running and jumping to improve fitness and muscular endurance. It offers a softer alternative to running because of a lower impact on the knees compared with running at the same speed [2]. Sport Nordic walking is a competitive activity that develops individual performance during sports events, and it requires special knowledge, training, and skills [39].

A German instructor explained that 'with Nordic walking, unless your doctor says no, there is no reason that you cannot participate at your own speed and pace. What you put in is what you get out'. According to many instructors, the most common group that prac- 
tised Nordic walking were a 'mixture of mums, selfemployed and retired ladies with ages ranging 38-71' and older people with 'an average age above 60'. Moreover, a few instructors from the USA and France offered Nordic walking sessions to children and adolescents. For example, a French instructor commented: 'I made an initiation to 13 years old people at school. It was really appreciated, a great experience'.

The activity is an effective workout that offers 'a full body workout, which burns more calories and takes all the stress and strain off the joints'. Nordic walking reduces the impact on the joints, allowing for walking faster and longer without feeling tired. A Finnish instructor noted: 'It gives a purpose to walking, helps those with balance and joint problems to walk further'. Also, owing to the active use of specially designed walking poles, it benefits coordination and synchronisation, giving walking a purpose. For example, a British instructor explained: 'they gave purpose and rhythm to the walk and more length and speed to the steps'.

Walking with poles is more effective than ordinary walking by bringing instant physical and mental benefits of exercising. An American instructor clarified: 'Everyone feels the benefits right away and from that comes confidence'. Also, many instructors stated that the increased intensity and body engagement in Nordic walking allowed practitioners to achieve healthand fitness-related goals. For example, a Dutch instructor who was a physiotherapist recommended the activity to his patients: 'I find it a good method to let my patients exercise and get a better physical condition. It decreases the weight on the joints and therefore can be done by people with joint problems'. Another British instructor viewed Nordic walking as a valid form of rehabilitation for cancer patients: 'My fellow instructor runs a special session at a cancer rehab unit once a week which is funded by the charity itself. She sees this to be where Nordic walking can do the most good'. Achieving health- and fitness-related goals through Nordic walking was a source of overall happiness and satisfaction for practitioners. As a Dutch instructor stated, 'I had some patients who couldn't walk well in normal life. With Nordic walking, they found that they can walk longer distances, also walking without the poles improved. They were very happy about that'.

\section{Motives for Nordic walking}

The common motivation for participation in Nordic walking was a mixture of extrinsic type of motivations, which referred to body-related motives, such as health and fitness. Several respondents perceived Nordic walking as beneficial for 'developing fitness' and started Nordic walking for their own health and wellness benefits. Others took up Nordic walking as an alternative exercise to running and cycling in order to exercise the whole body. For example, an American instructor practised Nordic walking to maintain fitness throughout the year: 'I'm an avid cross country skier, and it seemed a natural fit to me, especially given its roots in Nordic skiing'.

Nordic walking is frequently used as a form of physical activity in rehabilitation programs, and several respondents started practising it in order to recover from various leg injuries. A British instructor commented: 'I had fallen down a pot hole running and badly damaged my ankle so I wanted something that I could do to get my weight off without damaging myself again'. Furthermore, Nordic walking was perceived as an opportunity for a leisure career. For example, an American instructor explained: 'It was the next logical step in my love of the activity and my professional life'. Many respondents became Nordic walking instructors in order to share its health and fitness benefits and encourage people to be more physically active. A British instructor admitted: 'I wanted to pass on my knowledge to others and to get people of all ages to become fitter and to keep mobile after injury, surgery and getting older'.

In many countries, the activity was commercialised and Nordic walking instructors acted as leading distributors of Nordic walking poles. In a number of instances, the main reason for becoming instructors was to 'promote the Nordic walking poles business' and 'reach a larger number of customers'. In alternative circumstances, local organisations in need for Nordic walking instructors developed Nordic walking instructor networks and promoted the activity in local communities. For instance, a Danish instructor became engaged with the activity when 'The National Association of Elderly (Aeldre Sagen) needed voluntary instructors and arranged professional courses'.

\section{Social aspects of Nordic walking}

Nordic walking is a group activity that allows social interactions. In Nordic walking, practitioners have the opportunity for 'conviviality, group sharing experience' whilst exercising. Group Nordic walks create supportive sociality, which for many participants developed beyond the workout and became a centre of their social lives. A British instructor commented: 'I know that it has helped increase people's social circle, which has led 
to holidays together, dog sitting, coffees etc., so I think it has helped quality of life as well'. Many Nordic walking practitioners became close friends and did other things together, which improved their social lives and diminished feelings of loneliness. A British instructor noted: 'It is very sociable, and I have found that people who are now on their own (lost a partner) got the opportunity to make new friends and not be on their own'. Furthermore, close emotional bonds between the members in a group enhanced feelings of mental relaxation and enjoyment. For example, a British instructor stated: 'My walkers tell me they feel relaxed when they walk not worrying that anyone is judging them looking at their weight etc. They can just go out for an enjoyable walk and chat whilst burning calories'. However, a few instructors claimed that socialising as a key motivation for participation in Nordic walking might have been detrimental to achieving health benefits from the activity. For instance, a British instructor observed: 'as a group of instructors [...] we have found that they don't want to do any strength drills with tubes or things like that, they just like to walk and have a good chat'. In particular, extensive socialising between adults during Nordic walking practice prevented practitioners from focusing on correct walking technique, which resulted in not getting the full workout and reducing health benefits from the activity. A Danish instructor commented: 'I seem to detect many participants' superficial wish to partake in an activity, that they can speak about with family and friends as well as pretend to be active, rather than engage in a real effort to improve health and strength'.

The importance of the social aspects in Nordic walking can also be noticed in the promotion of the activity, which tended to focus on a word-of-mouth communication between the Nordic walking practitioners and non-practitioners. A British instructor recalled that he was introduced to Nordic walking when walking a 47-mile charity walk: 'I was getting a swollen ankle due to a metal plate in my let, so a friend recommended Nordic walking'. The respondents disclosed that they often learnt about the activity and its benefits through their friends and family members who had already practised Nordic walking. Another British instructor recalled: 'My family in Germany do Nordic walking regularly and introduced me to it in 2005'. Peer recommendation is a successful form of Nordic walking promotion owing to the informative role of instructors, whose key role is to share their knowledge and promote the activity. An Italian instructor commented: 'The first time I heard about Nordic walking was from a Nordic walking instructor who invited me to try'. The instructors also advise on specifications of Nordic walking equipment, technique, and health benefits of the activity.

\section{Barriers to Nordic walking}

In terms of the perceived constraints to Nordic walking, 2 types of barriers were identified: environmental and psychological.

Environmental barriers to Nordic walking referred to the weather and seasonal conditions, which prevented participation in the activity. According to an American instructor, 'weather is the No. 1 obstacle in maintaining a Nordic walking program'. Similarly, a British instructor stated: 'Weather has been our biggest barrier this year. A poor summer and all the flooding through the winter meant I have had to cancel walks due to severe weather warnings'. In addition, darkness during the autumn and winter months prevented Nordic walking practitioners from using the walking poles correctly. For instance, a British instructor commented: 'When the evenings get dark it is hard to Nordic walk due to not being able to walk on grass. In the dark you only want to walk on lit pavements but a lot of people prefer grass walking as they can use the poles properly'.

Another environmental barrier to Nordic walking was access to aesthetically pleasing natural environments. The respondents noted that walking in the same settings prevented them from enjoying the workout in the long term as walking 'the same routes every time is less inspiring,' which may suggest that repetitiveness of the physical environment could negatively influence participation in group Nordic walking sessions.

Psychological barriers to Nordic walking referred to a negative image of walking with poles. Several respondents noted that walking with poles had an unattractive image among general populations, which discouraged some practitioners to exercise in public spaces. Predominantly, the negative image of walking with poles was discussed by the British instructors: 'British people do not like to look silly, hence not willing to Nordic walk, understanding that it is not just for older people, poles are not walking sticks'. This may suggest there is a misunderstanding of the use of Nordic walking poles on flat surroundings amongst the British population because of its cultural and historical links to another type of walking, i.e. rambling. 


\section{Discussion}

This study aimed to explore the characteristics of the social aspects of Nordic walking from the INWA instructors' perspective, together with barriers and enablers in Nordic walking practices in various countries.

The findings indicated that the suitability of Nordic walking is wide-ranging and depending on personal capabilities, interests, as well as physical and social needs. The results suggested that in general, participants recognised the core values of health and fitness benefits of Nordic walking, which were associated with an active and correct use of the walking poles.

The active use of poles gave walking a purpose - a whole body workout. The importance of poles during the workout has been investigated by several studies [12, 15], suggesting that the active use of poles improved the upper body performance and reduced the perception of effort whilst Nordic walking $[2,11]$. Moreover, this study supported the previous research advocating that Nordic walking was beneficial for people in rehabilitation programs, recovering from leg injuries, and those who looked for an alternative exercise to running or cycling $[2,18,40]$.

Nordic walking is a sociable activity, in which companionship and friendship in a group were important positive aspects, strengthened and grew beyond the activity participation. The social aspects of Nordic walking were enhanced by close social bonds within walking groups and sharing positive experiences that helped reinforce a sense of belonging and diminish feelings of loneliness in many practitioners. This adds to the academic literature proposing that companionship and social support are the strongest influences on participation in physical activity [29, 32, 33, 41]. In addition, the social benefits of Nordic walking were related to the support of Nordic walking instructors in the initial and then regular activity participation when facing the psychological barrier of an unattractive image of walking with poles. The role of instructors was to provide a friendly atmosphere and positive feedback, which aimed to diminish the mental barrier to Nordic walking and provide satisfaction with the activity [5]. The instructors played a key role in teaching participants the correct walking technique, supporting and motivating them in their continuous improvements in order to enjoy the fitness and health benefits of the activity. They also encouraged regular participation by creating a supportive and friendly environment, in which practitioners felt comfortable and relaxed.
Nordic walking takes place outdoors and the access to diverse natural and built environments was the important environmental barrier and enabler for participation. This is in line with the previous studies suggesting that individuals were more physically active if they lived in areas with higher levels of mixed land use, street connectivity, safety of the environment, access to open spaces and other walking facilities, such as aesthetic attributes or streetlights, trust in the neighbourhood, use of private recreation facilities and sports fields [42, 43]. On the contrary, the repetitiveness of the environmental stimuli tends to negatively influence participation in walking [27]. Additional environmental influences on participation in Nordic walking were weather and seasonal aspects of the natural environment. For instance, the frequency and duration of walking for leisure decreases during colder and winter months as people are less likely to participate in outdoor activities when it is raining, snowing, icy, windy, or dark [44, 45]. Similarly, this study reports that the weather and seasonal conditions were the most common obstacle against regular participation in Nordic walking.

\section{Conclusions}

This research study is an initial investigation that has broadened the understanding of Nordic walking engagement and experiences.

The general findings correspond with previous research that suggested that Nordic walking is suitable for everyone who searches for the opportunities for an advanced workout without adding too much effort. The results also suggest that the activity develops personal capabilities and improves health owing to the active use of the Nordic walking poles. Furthermore, the study adds a further dimension to the theoretical knowledge of social benefits of Nordic walking, which were centred on building and maintaining strong social relationships between practitioners and instructors, offering social and emotional support within the groups. In particular, the social support of Nordic walking instructors provided instrumental assistance in motivating participants to improve in Nordic walking technique and in encouraging walkers to achieve personal fitness and health goals.

The study also contributes to the knowledge by proposing 2 types of perceived constraints to Nordic walking: the environmental and psychological barriers. Herein, the environmental barriers to Nordic walking were associated with the weather and seasonal con- 
ditions, and the diversity of built and natural environments; the psychological barriers referred to a negative image of walking with poles.

By considering personal, social, and environmental influences on participation in Nordic walking, this research study proposes that the activity can bring instant physical and social benefits of outdoor exercising.

\section{Limitations and future research}

This study must be considered in the light of its limitations. First, it provides descriptive accounts of a small number of international INWA Nordic walking instructors, who had a subjective view of the activity. Thus, the experiences and perceptions of 14 INWA instructors may not reflect the experiences of other Nordic walking instructors and practitioners and should not be generalised. Second, selection bias could potentially exist within the sample. It is possible that different results might emerge if non-volunteer individuals shared their experiences and knowledge on the subject. Finally, although the author offered an interpretation of the data, the interpretation was subjective and readers are also able to draw their own conclusions.

Despite methodological limitations, this research study can be seen as a beginning of a journey to explore social and psychological benefits of Nordic walking. Therefore, for a better understanding, additional research is required to evaluate and supplement the findings from this study. Subsequent studies could focus, for instance, on Nordic walking contributions to social and psychological well-being. Another interesting avenue for further research is the leisure perspective, for instance considering participation in Nordic walking as a leisure-time physical activity.

\section{Disclosure statement}

The author does not have any financial interest and did not receive any financial benefit from this research.

\section{Conflict of interest}

The author states no conflict of interest.

\section{References}

1. Piech K, Raczynska B. Nordic walking - a versatile physical activity. Pol J Sport Tourism. 2010;17(2):69-78.

2. Hagen M, Hennig E, Stieldorf P. Lower and upper extremity loading in Nordic walking in comparison with walking and running. J Appl Biomech. 2011;27(1):2231; doi: 10.1123/jab.27.1.22.

3. Song MS, Yoo YK, Choi CH, Kim NC. Effects of Nordic walking on body composition, muscle strength, and lipid profile in elderly women. Asian Nurs Res. 2013;7(1):1-7; doi: 10.1016/j.anr.2012.11.001.

4. Pellegrini B, Boccia G, Zoppirolli C, Rosa R, Stella F, Bortolan L, et al. Muscular and metabolic responses to different Nordic walking techniques, when style matters. PLoS One. 2018;13(4):e0195438; doi: 10.1371/ journal.pone.0195438.

5. Gotowski R, Zurawik M. Nordic walking instructor training in Great Britain and Poland - case studies. J Health Sci. 2013;3(11):421-434; doi: 10.13140/RG.2. 1.3562.8968.

6. Tschentscher M, Niederseer D, Niebauer J. Health benefits of Nordic walking: a systematic review. Am J Prev Med. 2013;44(1):76-84; doi: 10.1016/j.amepre.2012. 09.043 .

7. Hartvigsen J, Morsø L, Bendix T, Manniche C. Supervised and non-supervised Nordic walking in the treatment of chronic low back pain: a single blind randomized clinical trial. BMC Musculoskelet Disord. 2010;11:30; doi: 10.1186/1471-2474-11-30.

8. Sentinelli F, La Cava V, Serpe R, Boi A, Incani M, Manconi E, et al. Positive effects of Nordic walking on anthropometric and metabolic variables in women with type 2 diabetes mellitus. Sci Sports. 2015;30(1):2532; doi: 10.1016/j.scispo.2014.10.005.

9. Kocur P, Deskur-Smielecka E, Wilk M, Dylewicz P. Effects of Nordic walking training on exercise capacity and fitness in men participating in early, short-term inpatient cardiac rehabilitation after an acute coronary syndrome. A controlled trial. Clin Rehabil. 2009; 23(11):995-1004; doi: 10.1177/0269215509337464.

10. Keast ML, Slovinec D’Angelo ME, Nelson CR, Turcotte SE, McDonnell LA, Nadler RE, et al. Randomized trial of Nordic walking in patients with moderate to severe heart failure. Can J Cardiol. 2013;29(11):14701476; doi: 10.1016/j.cjca.2013.03.008.

11. Schiffer T, Knicker A, Montanarella M, Strüder HK. Mechanical and physiological effects of varying pole weights during Nordic walking compared to walking. Eur J Appl Physiol. 2011;111(6):1121-1126; doi: 10.1007/s00421-010-1739-5.

12. Kukkonen-Harjula K, Hiilloskorpi H, Mänttäri A, Pasanen M, Parkkari J, Suni J, et al. Self-guided brisk walking training with or without poles: a randomizedcontrolled trial in middle-aged women. Scand J Med Sci Sports. 2007;17(4):316-323; doi: 10.1111/j.16000838.2006.00585.x.

13. Hansen EA, Smith G. Energy expenditure and comfort during Nordic walking with different pole lengths. J Strength Cond Res. 2009;23(4):1187-1194; doi: 10.1519/ JSC.0b013e31819f1e2b.

14. Pellegrini B, Peyré-Tartaruga LA, Zoppirolli C, Bortolan L, Bacchi E, Figard-Fabre H, et al. Exploring muscle activation during Nordic walking: a comparison between conventional and uphill walking. PLoS One. 2015;10(9): e0138906; doi: 10.1371/journal.pone.0138906. 
15. Figard-Fabre H, Fabre N, Leonardi A, Schena F. Physiological and perceptual responses to Nordic walking in obese middle-aged women in comparison with the normal walk. Eur J Appl Physiol. 2010;108(6):11411151; doi: 10.1007/s00421-009-1315-z.

16. Reuter I, Mehnert S, Leone P, Kaps M, Oechsner M, Engelhardt M. Effects of a flexibility and relaxation programme, walking, and Nordic walking on Parkinson's disease. J Aging Res. 2011;2011:232473; doi: 10.4061/2011/232473.

17. Monteiro EP, Franzoni LT, Cubillos DM, de Oliveira Fagundes A, Carvalho AR, Oliveira HB, et al. Effects of Nordic walking training on functional parameters in Parkinson's disease: a randomized controlled clinical trial. Scand J Med Sci Sports. 2017;27(3):351-358; doi: $10.1111 /$ sms.12652.

18. Sprod L, Drum SN, Bentz AT, Carter SD, Schneider CM. The effects of walking poles on shoulder function in breast cancer survivors. Integr Cancer Ther. 2005;4(4): 287-293; doi: 10.1177/1534735405282212.

19. Malicka I, Stefańska M, Rudziak M, Jarmoluk P, Pawłowska K, Szczepańska-Gieracha J, et al. The influence of Nordic walking exercise on upper extremity strength and the volume of lymphoedema in women following breast cancer treatment. Isokinet Exerc Sci. 2011;19(4):295-304; doi: 10.3233/IES-2011-0430.

20. Fischer MJ, Krol-Warmerdam EM, Ranke GM, Vermeulen HM, Van der Heijden J, Nortier JW, et al. Stick together: a Nordic walking group intervention for breast cancer survivors. J Psychosoc Oncol. 2015;33(3):278296; doi: 10.1080/07347332.2015.1020465.

21. Soboleva AA, Iskakova GS, Khasanova RR, Andreev VI, Zagrevsky OI, Nikonova DU. The impact of Nordic waking trainings on social well-being of women at the age of 50-60. SHS Web Conf. 2016;28:01097; doi: $10.1051 /$ shsconf/20162801097.

22. Zurawik MA, Snape R, Carson J. 'Relaxing way to spend a day' or 'best way to keep fit and healthy'. Comparison of leisure experiences in rambling and Nordic walking and their contributions to well-being. Int J Sociol Leis. 2019 [in press]; doi: 10.1007/s41978-019-00038-y.

23. Zurawik M, Carson J, Snape R. "Magic mirror on the wall”: is Nordic walking or rambling better for your mental well-being? World Leis J. 2019 [in press]; doi: 10.1080/16078055.2019.1636857.

24. Addy CL, Wilson DK, Kirtland KA, Ainsworth BE, Sharpe P, Kimsey D. Associations of perceived social and physical environmental supports with physical activity and walking behavior. Am J Public Health. 2004;94(3):440-443; doi: 10.2105/ajph.94.3.440.

25. Cerin E, Leslie E, Sugiyama T, Owen N. Perceived barriers to leisure-time physical activity in adults: an ecological perspective. J Phys Act Health. 2010;7(4):451459; doi: 10.1123/jpah.7.4.451.

26. Caperchione C, Mummery WK, Duncan M. Investigating the relationship between leader behaviours and group cohesion within women's walking groups.
J Sci Med Sport. 2011;14(4):325-330; doi: 10.1016/j. jsams.2011.03.005.

27. Kassavou A, Turner A, French DP. The role of walkers' needs and expectations in supporting maintenance of attendance at walking groups: a longitudinal multiperspective study of walkers and walk group leaders. PLoS One. 2015;10(3):e0118754; doi: 10.1371/journal.pone.0118754.

28. Kwak L, Kremers S, Walsh A, Brug H. How is your walking group running? Health Educ. 2006;106(1):2131; doi: 10.1108/09654280610637175.

29. Courneya KS, Plotnikoff RC, Hotz SB, Birkett N. Social support and the theory of planned behavior in the exercise domain. Am J Health Behav. 2000;24(4):300308; doi: 10.5993/AJHB.24.4.6.

30. Trost SG, Owen N, Bauman AE, Sallis JF, Brown W. Correlates of adults' participation in physical activity: review and update. Med Sci Sports Exerc. 2002;34(12): 1996-2001; doi: 10.1097/00005768-200212000-00020.

31. Granner ML, Sharpe PA, Hutto B, Wilcox S, Addy CL. Perceived individual, social, and environmental factors for physical activity and walking. J Phys Act Health. 2007;4(3):278-293; doi: 10.1123/jpah.4.3.278.

32. Fletcher G, Behrens T, Domina L. Barriers and enabling factors for work-site physical activity programs: a qualitative examination. J Phys Act Health. 2008; 5(3):418-429; doi: 10.1123/jpah.5.3.418.

33. Ståhl T, Rütten A, Nutbeam D, Bauman A, Kannas L, Abel T, et al. The importance of the social environment for physically active lifestyle - results from an international study. Soc Sci Med. 2001;52(1):1-10; doi: 10.1016/s0277-9536(00)00116-7.

34. Green BC. Leveraging subculture and identity to promote sport events. Sport Manage Rev. 2001;4(1):1-19; doi: 10.1016/S1441-3523(01)70067-8.

35. Shove E, Pantzar M. Consumers, producers and practices: understanding the invention and reinvention of Nordic walking. J Consum Cult. 2005;5(1):43-64; doi: $10.1177 / 1469540505049846$.

36. Kumar R. Research methodology: a step-by-step guide for beginners. London: SAGE Publications Ltd; 2019.

37. VERBI MAXQDA 10. Software for qualitative data analysis. Berlin: Sozialforschung GmbH; 2010.

38. Marvasti A. Qualitative research in sociology. London: SAGE Publications Ltd; 2004.

39. Oksanen-Särelä K, Timonen P. Diversification of practice - the case of Nordic walking. In: Pantzar M, Shove E (eds.), Manufacturing leisure. Innovations in happiness, well-being and fun. Helsinki: National Consumer Research Centre; 2005; 198-213.

40. Morgulec-Adamowicz N, Marszałek J, Jagustyn P. Nordic walking - a new form of adapted physical activity (a literature review). Hum Mov. 2011;12(2):124-132; doi: 10.2478/v10038-011-0009-7.

41. Staats H, Hartig T. Alone or with a friend: a social context for psychological restoration and environmental 


\section{HUMAN MOVEMENT}

M. Zurawik, The social aspects of Nordic walking

preferences. J Environ Psychol. 2004;24(2):199-211; doi: 10.1016/j.jenvp.2003.12.005.

42. Giles-Corti B, Broomhall MH, Knuiman M, Collins C, Douglas $\mathrm{K}, \mathrm{Ng} \mathrm{K}$, et al. Increasing walking: how important is distance to, attractiveness, and size of public open space? Am J Prev Med. 2005;28(2 Suppl. 2): 169-176; doi: 10.1016/j.amepre.2004.10.018.

43. Feuillet T, Salze P, Charreire H, Menai M, Enaux C, Perchoux C, et al. Built environment in local relation with walking: why here and not there? J Transport Health. 2016;3(4):500-512; doi: 10.1016/j.jth.2015.12. 004.

44. McGinn AP, Evenson KR, Herring AH, Huston SL. The relationship between leisure, walking, and transportation activity with the natural environment. Health Place. 2007;13(3):588-602; doi: 10.1016/j.healthplace.2006.07.002.

45. Rutt CD, Coleman KJ. The impact of the built environment on walking as a leisure-time activity along the U.S./Mexico border. J Phys Act Health. 2005;2(3):257271; doi: 10.1123/jpah.2.3.257. 